\title{
Synthesis of extension models and analysis for sustainable agricultural technologies: lessons for extension workers in southwest, Nigeria. Ogunsumi, Lucia Omobolanle
}

\author{
Institute of Agricultural Research and Training, Obafemi Awolowo \\ University, Ibadan, Nigeria.
}

\begin{abstract}
Sustainable Agriculture is a way of farming that can be carried out for generations to come. Models are developed, utilized and adapted yet there are limitations. Problems still exist, as adapted models were not fully bringing adoption and sustainability of technologies, there is a need to have an understanding of farmers' situations and constraints from adapted models. It is imperative to evaluate different models over time and synthesis them in order to develop a model that will meet the need of farmers in Southwest, Nigeria.In-depth study devices were used to collect data, which were analyzed using appropriate descriptive and inferential statistics. The study further revealed that sustained use of technology contributed significantly to explain the variance in the net benefits of the investment analysis on maize, cassava and soybean technologies using adapted models. Improved productivity/high yield: Improved savings and investment, Better information accessibility, Better nutrition and health, High socio-economic status, Increased income and Increased social participation It could therefore be concluded that sustain agricultural technologies models adaptable to different situation and time contributed significantly to some dimensions of members' well-being and if technologies are sustained with full use of recommended inputs, it can alleviate the problems of peasant farmers and will obviously boost food production, as well as meeting the goal of being self sufficient in food supply to the ever increasing population.To achieve this, the following major recommendations were made: (i) Technologies should be cost effective and flexible for result oriented adoption and adaptation (ii) Governments should encourage Nigerians in their active working age to take to maize, cassava and soybean production. (iii) Effective cooperative societies should be organized in the study area for farmers. (iv) Government should fund research and extension to enhance sustainable agriculture. (vi) Finally there should be adequate provision of inputs required for whole adoption of technologies other than the present experience where partial adoption occurred on the field. Regular evaluation and monitoring of output should be encouraged to affirm that the stipulated research results are realised.
\end{abstract}

Keywords: Synthesis, extension models and agricultural technologies.

\section{INTRODUCTION}

The role of agriculture in the economy of Nigeria cannot be over emphasized. As a result, agriculture is expected to contribute to national development by serving as a source of abundant, affordable and high quality food for the people, a major sourcel of adequate and reliable supply of raw materials to industries, a source of decent employment and income for those engaged in agricultural production and a major contributor to foreign exchange earnings through export of tradable agricultural commodities (NISER, 2000).

There had been various policies formulated to encourage adequate and efficient agricultural production over time. The following are included:
- Farmers must be encouraged to participate in matters pertaining to agricultural development through formation of multi-purpose co-operatives.

- In the area of agricultural training, the Schools of Agriculture (now Federal Colleges), Universities of Agriculture and agricultural faculties in other universities need to have close cooperation with a view to developing agricultural departments and research on various sub-sets of agriculture. The states in cooperation with the Federal Government need to make it a policy to improve the national diets by year 2010; average calorie-intake would be raised from the present level of $200 \mathrm{gm}$ to the recommended level of 2400gm. (World Bank, 1997).

- Increase in food production should increase from 1.5 percent estimated annual growth rate to an average growth rate of 6 percent in the agricultural sector. 
This study revises relevant literature, theoretical postulations and empirical research findings concerning factors associated with technology adoption and sustainability. The major models are evaluated.

Transfer of Technology (TOT) Model: The pure transfer of technology model was the dominant approach of agricultural research in the 1950s. In this the generation and diffusion of innovation is a linear process from rich-country research institutes to poor-country research stations and from them to extension officers and to farmers.

The underlying assumptions were:

i. $\quad$ The most modern is the best;

ii. There is a single frontier of world scientific knowledge;

iii. Agricultural technology has global transferability irrespective of local ecological conditions; and

iv. Poor-country farmers are traditional and must undergo a quantum transformation to be modern (Oni, 2000).

The transfer of technology model sees the farmer as a passive recipient of new technology; if the farmer adopts the technology then the farmer is progressive. Failure of adoption is attributed mainly to psychological factors: irrationality, conservatism and traditionalism.

In this model, researcher break-through is transferred to extension for delivery to end-users. The model sees farmers as either adopters or rejecters of technologies, but not originators of either technical knowledge or improved practices (Chambers and Ghildyal, 1985, Sachs 1992). It views technology transfer as a linear process where the farmers are passive recipients of new technologies. Failure to adopt is usually attributed to psychological factors such as conservatism, traditionalism or irrationality. It usually succeeds in delivery technology only to progressive farmers (Rolings, 1991).

Adaptive Technology Transfer (ATT) Model: This model recognized the location-specific requirements of technology and farmers' behaviour are no longer seriously regarded as a barrier to adoption. The focus is to adapt new technology to local conditions and on removing the socio-economic constraints to adoption by farmers, such as the availability of complementary inputs of credit. This model was prevalent in 1970s and early 1980s. In this model the generation and diffusion of innovations remains a predominantly linear process with limited feedback from the farmers. The Training and Visit $(T \& V)$ extension system is based on this model.
The model proved a disappointing failure for resource poor farmers operating under diverse ecological conditions with complex cropping systems, poor or absent input markets and high risk climatic conditions (Chambers and Jiggins, 1987).

Farming Systems Research (FSR) Model: The model (FSR) emerged in the mid-1970s and became prevalent in the 1980s to ensure the transfer of technologies to resource-poor farmers. FSR has greatly changed the status of the farm households and the farm system in the generation and diffusion of new technology. This was done by placing emphasis on discoveries made by farmers themselves; goals and constraints from on - farm trails and farmers' participation in the testing of new varieties or methods, and instituting interactive feedback mechanism between farmers and researchers. Under the FSR philosophy, the constraints faced by resource-poor farmers are taken seriously and the likelihood that such constraints can be removed is treated with caution. The technology must be adapted to the constraints not vice versa.

Farmer-First Research (FFR) Model: FFR came out of the argument against the FSR solution to the matching of research priorities with farmer needs The model does not draw not enough on the knowledge and experimental skills of farmers. The expected staff of the research station - agric specialized scientists, social scientists and their assistants remain firmly in control of the data elicited from farmers, the design of on-farm trails and the nature of the technology eventually recommended for wide spread adoption. The farmer-first model (so called due to Chambers et al 1989 but originating in the 'farmer-back-to farmer' model of Rhoades and Booth, 1982) envisages the supply and demand for innovations as a circular process beginning and ending with farmers, rather than a linear process beginning with scientists and ending with farmers. The circle has no particular point of departure since it involves a continuous interaction; on a basis of partnership between scientists and farmers and the components of the process need not take a particular order.

Farmer-Back to-Farmer (FBT) Model: This is used for generating an agricultural technology that is acceptable to the farmer. The model outlines an alternative approach to solving farm level technological problems. It was developed to improve food production in developing countries by placing emphasis on interdisciplinary teams in the identification, generation and transfer to farmers of 
appropriate technologies (Rhoades and Booth, 1982).

The basic philosophy upon which the model is based holds that successful agricultural research and development must begin and end with the farmers. It also believes that farmers are more likely to accept changes if they actively participate in the final research process as shown in Figure 1.

The FBF model also views farmers as coresearchers, developers, and extensionists as in development of technology transfer models. partners who can provide crucial inputs in determining what problems to address and how to proceed (Chambers et al, 1989). The approach moves the intended beneficiaries out of the role of passive receivers, typical of early agricultural communication models into the role of active participants, and reflects the increasing influence of social

scientists

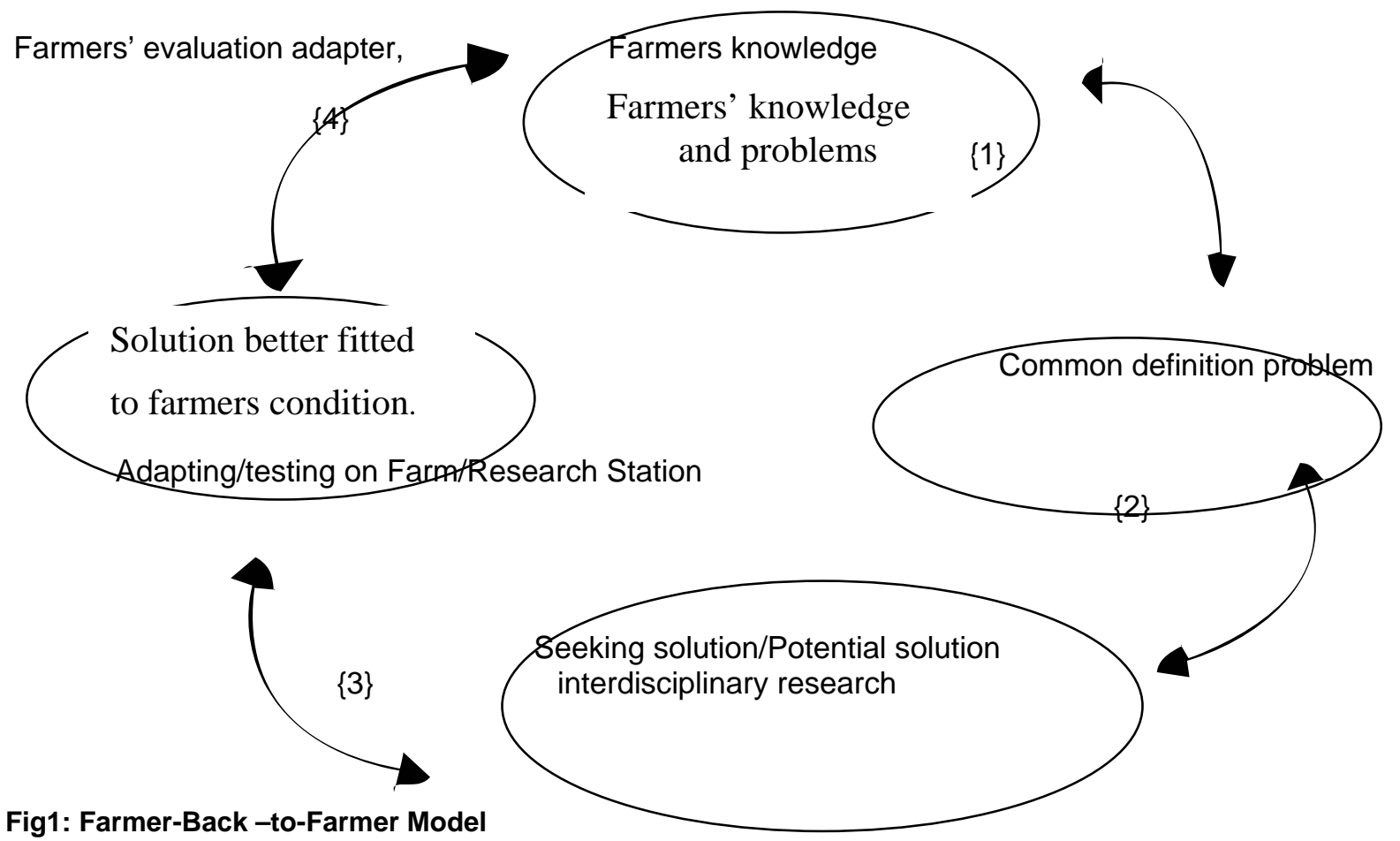

Source: Adapted from chambers et al (1989)

Farmer-First-Farmer-Last (FFFL) Model : The Farmer-First-Farmer-Last is a model proposed by Chambers and Ghildyal (1985). It entails a fundamental reversal of learning and research strategy. Research problems and priorities are identified by needs and opportunities of the farm families rather than by the professional preferences of the scientist.

This model generates varieties of choices to enable farmers to vary, and diversify their farming system. It stresses, illustrates and explores the ability of the resource poor farmers to experiment, adapt and innovate. It sees the starting point of development as an active and equitable partnership between rural people researchers and extensionists (Chambers et al, 1989). The outsiders are viewed primarily as catalysts or facilitators of the open exchange of ideas and information between various interest groups. The proponents of this model emphasise the importance of rural people's knowledge, which they believe can be blended into scientific pool of knowledge.

This is said to be based on the principle that greater attention needs to be paid to on-farm conditions and that farmers need to play a more active role in agricultural experimentation. The authors claim that greater participation of farmers in on-farm research will result in a technology development process more attuned to local conditions and properties. Conventional on-farm research largely designed and managed by external researchers was thus transformed into Farmers Participatory Research (FPR) where farmers become the central actors in research and experimentation process. 
Beyond Farmer First (BFF) Model: Scones and Thompson (1994) introduced the BFF model. It points to where the farmer-first approach lacks certain analytical depth and presents more radical programme that incorporate socio-politically differentiated views of development. The model highlights gender, ethnicity, class, age and relation having important implications for research and extension practice. It emphasizes that different types of local and non-local people hold many divergent, sometimes conflicting, interests and goals, as well as differential access to vital resources. Knowledge, which is diffuse and fragmentary, emerges as a product of the discontinuous and inequitable interactions between the actors i.e. researchers, extensionists and farmers (IIED, 1994).

This model increases the recognition of farmers' own research and experiment investigation. This model reveals that experimentation is a process of injury that runs continuously as a part of farmers' own agricultural performances.

The central focus is for agricultural researchers to appreciate and understand the process of agricultural experimentation and seek ways of articulating onfarm research with farmers own research projects and modes of injury. Scones and Thompson, (1994), concluded that this can be in three ways:

- The recognition of scientific investigation and those farmers can be taught improved forms of experimentation using scientific method such as controlled plot companions or enhanced examination techniques;

- Second, some farmers already follow scientific methods of inquiry such that agricultural innovation results from the progressive accumulation of experimental insight. It contends that effective linkages with formal science are best affected through those farmers who follow such method of analysis; and

- Third, it emphasises farmers' own experimentation and states that this should be treated as a form of inquiry in its own right and not be judged by criteria set by scientific reasoning.

Trying to force farmers' own methods of inquiry into a straight jacket provided by researchers constructs undermines the value and potential of farmers' experimentation.

Synthesis and Analysis of These Models: The common denominator of these models is the focus on generation and dissemination of technologies to farmers. These paradigms however, did not clearly define their situations under different political, environmental technical and institutional factors like that of Nigeria. The question of how applicable they are to the Nigerian setting and the sustainability of the adopted technologies for improved farmers' standard of living is yet to be answered.

In view of these, this analysis proposes a framework for analysing the sustained use of agricultural technology on farmers' productivity.

The framework is depicted as Figure 2 the framework is based on the following assumptions and conditions:

1. There are Research Institutions in Nigeria producing agricultural technologies such include IAR\&T, NCRI, NIHORT, CRIN and NIFOR inter alia;

2. There are extension outfits, which rely on research institutes

3. The personal characteristics of the farmers affect their adoption and sustained use of technology;

4. Sustained use of technology depends on awareness, attitude, contact with extension services; and

5. Farmers output can be increased by sustained use of improved technologies

Explanation of the Framework: The conceptual framework was based on the premise that adopted agricultural technologies were not fully adopted, can be sustained or abandoned (Dependent variable) through the influences of demographic, economic, socio- cultural and environmental factors (Independent variables) research /extension linkage systems and political factors (Intervening variables). The out put of the interaction is expected to bring an improved level of living for sustained group and depressed level of living for abandoned group. This conceptualisation was influenced by the work of Swanson et al (1988) and Kaimowitz et al (1989) on analysing the agricultural technology system (ATS).

To analyse the sustained use of agricultural technology on farmers' productivity, the conceptual framework highlights the interactive in process with respect to relationship between the categories of independent variables and their components.

It also outlined an exploratory process of analysing the sustained use of agricultural technology provided by the research and extension organisations as well as the influence on the farmers' output. 
6

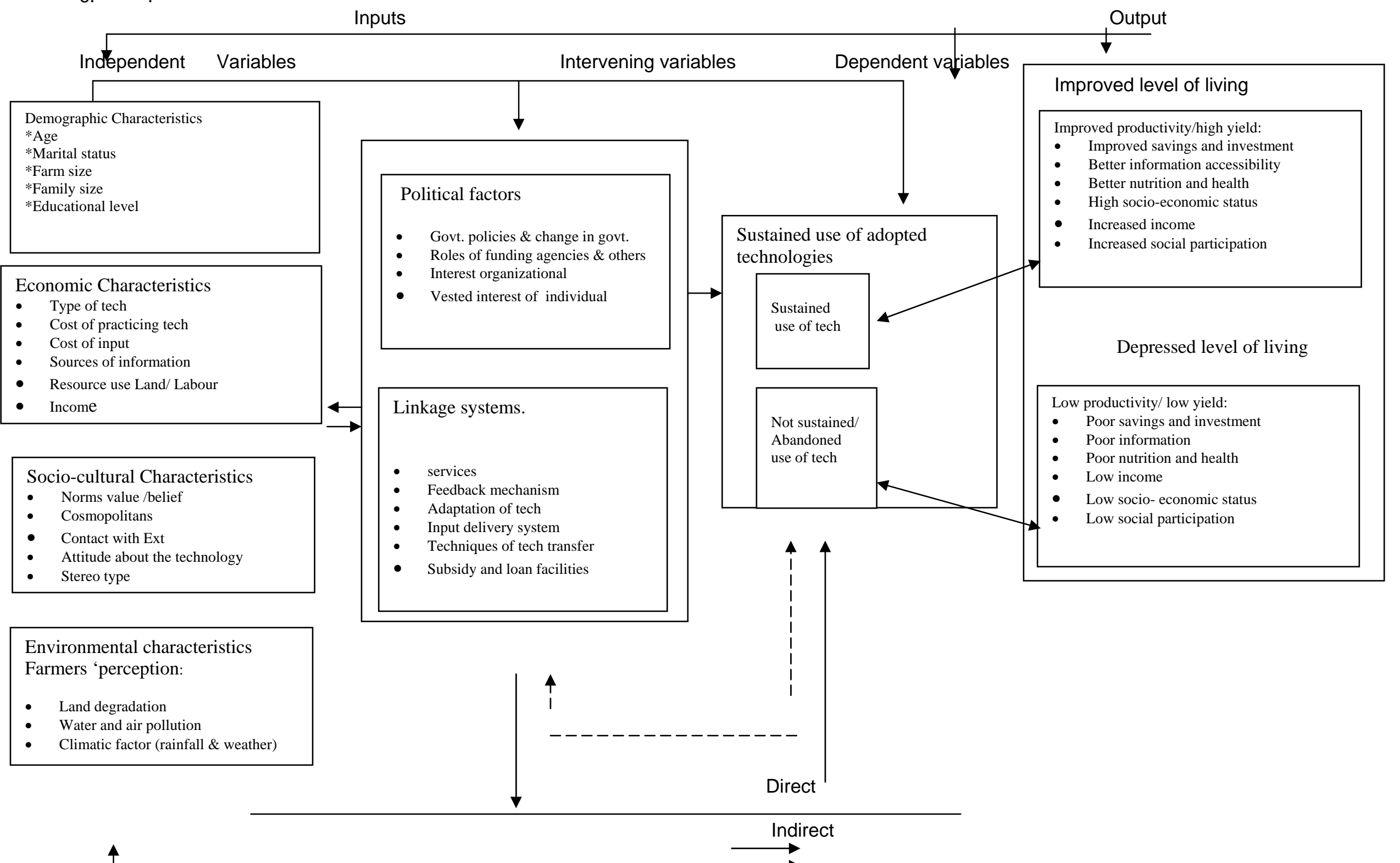

Fig 2: Conceputual framework of the analysis of sustained use of $\overline{\text { ag }}$ ricuttural technologies on farmers' productivity in south west, Nigeria 
The diagrammatic representation of this model can be interpreted as a process in which the predictive contributions of the independent variables (such as age, gender, marital status, educational background, farm size, income, attitude and contact with extension agents) affect the dependent variable.

This presents the response of technology as the ultimate assessment of any technology transfer process. Sustained use of technology is dependent on a number of intervening variables, which directly or indirectly influence the variables.

The intervening variables are in two categories:

1. Research/ Extension linkage systems \{linkage method, type of technology, feedback mechanism, adaptation of technology, input delivery system, techniques of technology transfer and access to input\}.

2. Political \{government policies, unstable political system, roles of funding agencies and other stakeholders, vested interest of developing Institutions /organisation and individuals\}.

These intervening variables are expected to be tested to know the sustained use of technologies by of farmers. The expository characteristics (awareness, attitude and contact with extension services) are also expected to be tested and determine their influence directly or indirectly the dependent variables.

\section{CONCLUSION}

By and large, from the generality of the evidences of the study, it is concluded that if sustained users are organized and run in a manner that guarantees active participation, adequate and timely supply of inputs at affordable prices, they could contribute immensely to the improvement of the living conditions of the members and that of the rural community in general.

\section{REFERENCES:}

Chambers, R and Jiggings, J. 1987. Agricultural Research for Resource Poor Farmers.

Chambers, R, A. Pacey and L. A. Thrupp, 1989. The Farmer first and Farmer Innovation and Agricultural Research, London: Intermediate Technology Publications.

Chambers, R. and Gildyal, B. 1985. Agricultural Research for Resource Poor Farmers- The Farmer first and Farmer Last Model. Journal of Agricultural Administration No20: Pp. 1-30.

Kaimowitz, O. Snyder, M. and Engel, P 1991. A Conceptual Framework for Studying Links between Agricultural Research and Technology Transfer in Developing Countries in: Making the Link Agricultural Research and Technology Transfer in Developing Countries. West view.

Nigerian Institute for Social and Economic Research (NISER) 2000. NISER Review of Nigeria Development: The state of Nigeria

Development. Pp 7-48; 173-215

Ogunsumi, L. O. 2004. Analysis of Sustained use of Agricultural Technologies on Farmers' Productivity in Southwest, Nigeria. Ph.D. Dissertation, Department of Agricultural Economics and Extension, Federal University of Technology, Akure, Nigeria.

Oni, O. A 2000. A Recursive Analysis of Enterprise Combinations Among Cocoa Farming Households in Ondo State, Nigeria. Unpublished PhD Dissertation Department of Agricultural Economics, University of Ibadan.

Rhoades, R.E. and Booth P.H. 1982. "Farmer Back to Farmer: A Model for generating acceptable Agricultural Technology" Agricultural Administration Journal Vol. 11. No 2. Oct. Applied Science Publishers Ltd. England. Pp. 127-137.

Rolings, M. 1991. "The Agricultural Research Technology Transfer Interface. A knowledge system perspective". In making the link.Agricultural Research and Technology Transfer in Developing Countries. Kaimovitz (ed). ISNAR Publication.

Sachs, W. 1992. The Development Dictionary: A Guide to Knowledge As Power Z ed. Press London. Pp. 72101.

Scones, I. and J. Thompson 1994. Beyond Farmers First Rust: Rural people knowledge, Agricultural Research and Extension practice. Intermediate Technology Publication, London Pp 1-12.Uspton M (1967): Socio Economic Survey of some farm families " Nigeria" Bulletin of Rural Economics and biology Vol 2 No 3.

Swanson, B. E; C. M Sands and Peterson, W. E 1988. Analyzing Agricultural Technology System: Some Methodological Tool in Proceeding of the ISNAR/Rutgers Agricultural Technology Management Workshop 6 - 8 July Rutgers University New Jersey U. S. A.

World Bank 1997. Nigerian Agricultural Research Project. Report on Southwest Zone of Nigeria Plan. 